\title{
What are the Barriers to Effective Nurse Leadership? A Review
}

\author{
By Vickie Hughes*
}

\begin{abstract}
The aim of this review was to examine the evidence regarding barriers to nurse leadership. Nurses comprise the largest segment of the healthcare workforce. Nursing has consistently been ranked as the most respected position by United States Gallop Poles with the exception of 2011 when fire fighters were ranked number 1. However, the percentage of nurse hospital and health system board members dropped from 6\% in 2011 to 5\% in 2014 (American Nurses Association 2015). Why are nurses not moving into these highest levels of healthcare organizational leadership? Historically it has been difficult to find staff nurses willing to pursue leadership positions. What are the barriers for staff nurses to move into leadership positions? What are the barriers for effective nurse leadership? An electronic literature search for "nurse leadership barriers" was conducted using Pubmed, CINAHL, Health Source: Nursing/Academic Edition, and Cochrane Collection Plus databases published between January 1, 2006 and January 1, 2017. Multiple barriers to nurse leadership development were identified from the literature. Resources for leadership preparation was not seen as much of a priority for nurses as in some of the other healthcare disciplines.
\end{abstract}

Keywords: Advancement, Barriers, Leadership, Nurse, Role Enactment

\section{Introduction}

Nursing leadership is a very complex concept. Nurse leaders serve at different levels within healthcare organizations and junction in various types of leadership roles. Some of these roles may be as clinical nurse leaders, executive nurse leaders, mid-manager level leaders, research leaders, academic leaders, and even informal leaders within organizations. Nurses are even serving on healthcare boards and as Chief Officer Executives for hospitals. The Institute of Medicine Report (2010) recommendation is that nurses should be included as representatives on public, private, governmental, and executive health care decision making teams. But the number of nurse leaders serving in these executive roles is lower than what might be expected. According to a 2014 survey conducted by the American Hospital Association's Center for Health Care Governance found a trend in declining numbers of clinically oriented board members. For the 1,000 hospitals examined only $20 \%$ had physicians on their boards and only $5 \%$ had nurses (American Hospital Association 2014). What is even more surprising is that out of the 5,627 registered hospitals in the United States, only about 281 of them have nurses serving on their boards (American Nurses Association 2016).

Nurses enter into leadership roles for many different reasons. Bondas (2006) identified four different paths for Finnish nurse leaders based on a qualitative analysis of 68 nurse leaders' responses in a semi-structured questionnaire. The four themes identified during the study include: the path of ideas, the career path, the path of chance, and the temporary path. The path of ideas is when the nurse makes a conscious choice to become a nurse leader. This type of leader often seeks new knowledge and education to be prepared to function in the role. The

\footnotetext{
* Assistant Professor, Johns Hopkins University, Baltimore, Maryland, USA.
} 
leader who chooses the path of ideas is characterized by wanting to make a difference in patient care, the particular unit, or the organization through an intentional pursuit of a leadership position. The nurses who choose the career path explicitly want to become formal leaders for different reasons. The career path leaders may pursue the role in order to work daytime hours, to move more freely around within the organization, to obtain more control of work hours, to earn a higher salary, to be challenged more at work, and possibility of increased visibility in the organization. The path of chance is when a nurses is offered a leadership position without seeking the leadership role. Sometimes the path of chance happens when a vacancy in a leadership position occurs unexpectedly. In the study, $31 \%$ of these participants stated that they had never thought about working in a leadership role. These nurses moved into the leadership position because someone encouraged them to perform in the leadership role. The final theme involved the temporary path of leadership. This path was similar to the path of chance, but slightly different. In the temporary path there is an opportunity for a leadership trial with the option to return to previous position. The nurses functions as a substitute until a formal leader is hired for the position. The experience of a leader substitute was negative if the person never had the chance to lead again within the organization. Some of the temporary path leadership experiences created bitterness (Bondas 2006).

The evidence is clear that nurse leaders can and do make an impact. Effective nurse leadership has been demonstrated to have a positive effect on patient safety (Collette 2015), the development of a safety climate (Lievens and Vlerick 2013, Liang et al. 2016), lower patient mortality (Wong et al. 2013), safe medication practices (Farag et al. 2017), patient satisfaction (Wong et al. 2013) and the quality of patient care (Ma et al. 2015). Furthermore, specific nursing leadership styles have been shown to positively influence nurse job satisfaction (Ma et al. 2015, Morsiani et al. 2016), nurse intent to stay (Abualrub and Alghamdi 2012), nurse engagement (Lewis and Cunningham 2015, Brewer et al. 2016), nurse innovation (Weng et al. 2015) and to reduce nurse incivility (Bortoluzzi et al. 2014, Kaiser 2017). On the other hand, ineffective nurse leadership is associated with negative effects on nurse satisfaction, nurse effectiveness, and nurse productivity (Cummings et al. 2010).

In the complex, ever changing healthcare system it is vital to have effective nurse leaders. Developing effective nurse leaders may be more important now than at any previous time in history as many nurses are nearing the age of retirement. This leadership review will examine barriers associated with nurses developing effective leadership skills, enacting their leadership roles, and moving into leadership positions.

\section{Purpose}

The purpose of review is to analyze the published evidence to identify barriers to effective nurse leadership. 


\section{Methodology}

An electronic literature search for "nurse leadership barriers" was conducted using the Pubmed, CINAHL, Health Source: Nursing/Academic Edition, and Cochrane Collection Plus databases. Inclusion criteria included English language, human studies, full text available articles, and published dates between January 1, 2006 and January 1, 2017. Abstracts for the identified articles were reviewed for relevance and duplicate citations were removed. Reference lists were also reviewed for relevancy, resulting in a total of 11 papers being included in the review.

\section{Analysis of Quality}

The 11 studies identified based on inclusion criteria were reviewed and categorized according to level of evidence and the quality of rating of scientific evidence based on Johns Hopkins Evidence Rating Scales (Newhouse et al. 2005). Nine of the studies were considered as Level 3, one study was considered as a Level 4, and one study was a Level 5 (opinion paper) based on the strength of the evidence. The 11 studies were assessed as good to high quality based on the rating scale.

\section{Results}

The findings from this review indicate that there are multiple barriers to leadership development for the different types of nurse leadership roles. In addition, there are multiple barriers to nurse leaders enacting their leadership roles. Finally, this study identified barriers to nurses moving into board positions for healthcare organizations.

Several barriers for leadership development were identified during this review for registered nurses. Peltzer et al. (2015) conducted an on-line survey of 971 registered nurses in Kansas (United States) to explore their leadership development needs. Out of the 971 surveyed, 62\% self-identified as being a leader. The employment position of 911 of the participants fit into the common leadership categories reported in the study. From a list of leadership positions, the participants identified their desired goal. The distribution between formal and service-oriented leadership positions was close to an equal distribution. The most frequent desired leadership roles were health care organization volunteer, administrative leader and community organizational leader. The most frequent identified barrier to developing leadership skills to serve in these roles was time constraints. The respondents identified insufficient time during and outside of work to pursue leadership development. Other barriers included limited organizational leadership opportunities, lack of funding for advancement as a leader, and perceived need for further leadership development before serving in a leadership role. Out of the 971 surveyed, 10 nurses reported that they did not perceive any barriers to their leadership development (Peltzer et al. 2015). 
Keys (2014) conducted a qualitative study of Generation X nurse managers to examine their perspective on professional success and personal and professional fulfillment. The nurses in this study also identified limited organizational opportunities for upward mobility as a barrier to their leadership development. Another concern was that the nurses did not attend any formal leadership training and felt that they were not educationally prepared for leadership prior to moving into the position, particularly in the areas of business and management skills. Some nurses commented that they believe having their Master's Degree in nursing prior to moving into the position would have better prepared them for the role. Many of the participants sought out tools and skills to develop leadership skills through formal education and nurse manager training programs. In addition, these nurses described inflexible organizational cultures, feeling stereotyped and undervalued, and a need to be available at all times as barriers to professional success and fulfilment. The most frequent mention barrier was not understanding the gravity and demands of the position prior to accepting the role. Specifically, the nurse managers did not realize that they would have the 24-hour responsibility for the unit (Keys 2014).

Lack of leadership resources was also one of the barriers for nurses moving into leadership roles identified in a survey of 3,498 registered nurses in Florida (Denker et al. 2015). Of those surveyed, 1012 (75\%) identified nurses not being seen as revenue generators compared to physicians and the absence of nurse visibility in policy making $(947,70 \%)$ as major barriers to nurses moving into leadership roles within healthcare. Additional barriers identified include a lack of a unified voice among nurses, public perception of nursing roles, and current compensation for nurses (Denker et al. 2015).

Not only are there barriers to leadership development for nurses, but there are also barriers for nurses in enacting their leadership role. Mass et al. (2006) conducted a survey of 34 senior nurse leaders and 33 middle-level nurse leaders in Canada. The participants identified a range of barriers that inhibited the enactment of nursing leadership roles. The constant uncertainty and restructuring of the health care system was seen as a barrier to nursing leadership. The "constant upheaval" and workload that result from some of the dramatic pendulum shifts in priorities are rarely evaluated for the impact of the change on patient care or staff. Another barrier identified was the lack of role clarity. The "Nursing" has been taken out of the leadership role titles to be replaced with such titles as Team Leader, Program Manager or Division Manager. The final barrier identified was the long work hours related to the dramatically increasing workload across the nursing sector. The middle managers expressed considerable anxiety about time pressures and their impact to perform well in their current role and manage their family and other responsibilities. The perception that senior nurses were expected to manage even more complex workloads in conflict-ridden environments resulting in an even harder work-life balance to achieve was a disincentive for middle-level managers to move into the more senior roles (Mass et al. 2006).

Furthermore, there are barriers for nurses enacting the full range of responsibilities of their leadership roles. One of the key nurse leadership components is supervision. Rankin et al. (2016) examined the facilitators and 
barriers to the increased supervisor role of senior charge nurses in Scotland. The investigators conducted an online questionnaire of 60 senior charge nurses and semi-structured interviews of 12 senior charge nurses. They identified four key factors that acted as a barrier to efficient delivery of supervisory role. The demands and expectations of the role of senior charge nurse involved juggling multiple professional roles to include nurse, educator, ward manager, mentor, role model and supervisor. The demands for competing priorities was identified as a barrier to the charge nurses effectively managing a patient case load with clinical supervision time. Another perceived barrier was the perception of growing time constraints related to an increased request for paperwork, managing availability of beds, and putting in extra work hours to cope with increased work load. Managing staff levels was identified as the main barrier to supervision. Ensuring appropriate skills mix, managing staff rotations, and dealing with the proportions of bank staff were very time consuming (Rankin et al. 2016). The final barrier identified to the role of senior charge nurse was the inadequate support for the role. The nurses identified a lack of coaching and mentoring, the lack of a formal induction into the role, a lack of an effective process for having key concerns addressed and frequent changes in policy with insufficient time to embed changes as key aspects of the experienced lack of support (Rankin et al. 2016).

Dwyer (2011) conducted a systematic review of registered nurses as managers or clinical leaders in residential aged care facilities. A total of 8 qualitative studies from Ireland, Sweden, Australia, New Zealand and the United States met the inclusion criteria for the review. The investigator summarized the barriers to leadership development for registered nurses working in aged care. The barriers include a lack of specific education that is focused on clinical leadership and health team management, feeling devalued by the system, and a lack of a structural pathway of learning and development for the registered nurses (Dwyer 2011).

Barriers to clinical leadership development was investigated through a random sample survey of 3,000 nurses and midwives in Ireland (Fealy et al. 2011). An 89 item instrument was developed from a critical review of the literature on dimensions of clinical leadership to be used in the survey. Over two thirds of the sample reported not having attended any training for the leadership role. The perceived barriers to clinical leadership development were highest in the category of influence in the interdisciplinary and organizational working. The staff grade nurses and clinical manager grades differed significantly on their responses on barriers in the interdisciplinary relationships and recognition barriers. The authors concluded that the relative position of the nurse within the organization and not the level of experience may be the factor that influenced the way barriers were perceived (Fealy et al. 2011).

In addition to registered nurses, advanced practice nurses also experience barriers to leadership development. "The Institute of Medicine committee took particular note of the legal barriers in many states that prohibit advanced practice registered nurses from practicing to their full education and training" (Institute of Medicine 2010: 1). However, practicing to the full scope of training is not only an issue within the United States. According to Bressan et al. (2016), 
advanced nursing roles are less developed in Italy as compared to the other European countries which creates a barrier to the clinical leadership development. According to the authors, the roles of Advanced Nurse Practitioner and Nurse Specialists do not formally exist in Italy (Bressan et al. 2016). Furthermore, a lack of training and research resources hinder the development of the clinical nurse leader (Bressan et al. 2016).

Elliott et al. (2016) conducted a literature review to identify barriers and enablers to advanced practitioner's ability to enact their leadership role. The investigators reviewed 34 papers published between 1984 and 2015. The studies were conducted in the United Kingdom, Canada, Northern Ireland, New Zealand, Australia, the United States and Taiwan. The investigators identified 13 barriers and 11 enablers using a data extraction framework for advanced practitioners' ability to enact their leadership role (Elliott et al. 2016). The 13 barriers were placed into four themes related to the healthcare system, the organizational level, the team and advanced practice. The 13 barriers to leadership identified include: a lack of opportunity to work at strategic level; a large clinic case load (most frequent); a lack of support from nursing management, medical consultants and clinical staff; a lack of clarity/understanding of leadership and research role; a lack of administrative support; a lack of authority/position within organization; insufficient resources; a lack of time/support for research; a lack of critical mass or being in a lone position; a lack of leadership skill development and education; a lack of advanced practitioner leadership attributes; the lower level of education; and limited time within role.

For nurses desiring to participate in health policy, additional barriers were identified in a study by Shariff (2014). The identified barriers included: a lack of involvement, the negative image of nursing, a lack of enabling structures, a process which exclude nurses, and a lack of available resources (Shariff 2014). Overcoming these barriers will be necessary if nurses are to expand their leadership role in policy and governing organizations.

\section{Synthesis of Findings}

In summary, barriers identified for nurse leadership development include a lack of funding (Peltzer et al. 2015), time constraints (Peltzer et al. 2015), a lack of specific education that focused on clinical leadership and health team management (Dwyer 2011), a lack of a structured pathway for developing nurse leaders (Dwyer 2011), and a lack of available leadership training (Fealy et al. 2011, Keys 2014). Barriers to nurses moving into higher leadership roles include: limited organizational opportunities (Peltzer et al. 2015), lack access to working at the strategic level (Elliott et al. 2016), inflexible organizations (Keys 2014), nurses not being seen as revenue generators compared to physicians and the absence of nurse visibility in policy making (Denker et al. 2015), a lack of formal leadership training (Fealy et al. 2011, Keys 2014), and nurses feeling devalued by the system (Dwyer 2011). In addition, nurses may choose to not seek out the middle nurse manager or executive leadership roles because of the time constraints, long hours, conflicting priorities, and stress related to the leadership position (Table 1). 
Table 1. Barriers Related to Nurse Leadership Development

\begin{tabular}{|c|c|c|c|}
\hline $\begin{array}{c}\text { Barriers to } \\
\text { Nurse } \\
\text { Leadership } \\
\text { Development }\end{array}$ & $\begin{array}{l}\text { Barriers to Nurse } \\
\text { Leadership } \\
\text { Advancement }\end{array}$ & $\begin{array}{l}\text { Barriers to Nurse } \\
\text { Enacting Leadership } \\
\text { Roles }\end{array}$ & $\begin{array}{c}\text { Barriers to } \\
\text { Nurses Serving } \\
\text { on Boards }\end{array}$ \\
\hline $\begin{array}{l}\text { - time } \\
\text { constraints } \\
\text { - lack of } \\
\text { available } \\
\text { leadership } \\
\text { education } \\
\text { - lack of } \\
\text { structured } \\
\text { nurse leader } \\
\text { pathway } \\
\text { - lack of } \\
\text { funding }\end{array}$ & $\begin{array}{l}\text { - lack of access to working } \\
\text { at strategic level } \\
\text { - limited organizational } \\
\text { opportunities } \\
\text { - inflexible organizations } \\
\text { - not being seen as a } \\
\text { revenue generator } \\
\text { - no visibility in policy } \\
\text { making } \\
\text { - nurse feeling devalued in } \\
\text { system } \\
\text { - time demands, } \\
\text { conflicting priorities, and } \\
\text { stress related to middle } \\
\text { nurse or executive } \\
\text { leadership roles }\end{array}$ & $\begin{array}{l}\text { - lack of support } \\
\text { - lack of role clarity when } \\
\text { "nursing" removed from } \\
\text { job title } \\
\text { - large clinical case load } \\
\text { - lack of clarity of } \\
\text { leadership and research } \\
\text { role } \\
\text { - lack of administrative } \\
\text { support } \\
\text { - insufficient resources } \\
\text { - time constraints } \\
\text { - state board regulations } \\
\text { that prevent advanced } \\
\text { practice nurses from } \\
\text { working within their } \\
\text { scope of practice } \\
\text { - limited resources for } \\
\text { training }\end{array}$ & $\begin{array}{l}\text { - negative } \\
\text { image of } \\
\text { nursing } \\
\text { - lack of } \\
\text { enabling } \\
\text { structures } \\
\text { - process which } \\
\text { excludes } \\
\text { nurses } \\
\text { - lack of } \\
\text { available } \\
\text { resources } \\
\text { - lack of } \\
\text { involvement }\end{array}$ \\
\hline
\end{tabular}

Furthermore, there are several barriers identified that hinder nurses enacting their leadership roles. Mass et al. (2006) identified two barriers to nurse leadership enactment as a lack of role clarity with "nursing" being removed from the job titles and a constant uncertainty resulting from restructuring of the health care system. Rankin et al. (2016) identified middle managers having to juggling multiple professional roles, time constraints, and a lack of support as barriers to effectively executing the clinical supervision aspect of leadership role. Elliott et al. (2016) identified barriers to advanced practice nurses enacting their leadership roles. Some of these barriers include: a large clinic case load, lack of support from leadership, lack of clarity of leadership and research role, a lack of administrative support, time constraints, and insufficient resources (Elliott et al. 2016). In addition, within the United States, many state boards of nursing prohibit advanced practice nurses from working to the full scope of their training (Institute of Medicine 2010). In Italy, advanced practice nursing roles may be less developed than in the other European countries. Limited resources for training and research for the advanced nurses (Bressan et al. 2016) may be barriers in Italy for nurses enacting their clinical leadership roles.

The Institute of Medicine (2010) recommended that nurses be included as representation on public, private, governmental, and executive health care decision making teams. However, there are barriers to nurses serving on boards. Shariff (2014) identified a lack of involvement, the negative image of nursing, a lack of enabling structures, a process which exclude nurses, and a lack of available resources as barriers that hinder nurses from participating as board members for healthcare organizations. 


\section{Discussion and Recommendations}

Several of the studies indicated barriers to leadership development. The lack of a formalized training course and a clear progression for leadership development might be eliminated as barriers to leadership development through a formal succession plan in which one or more leadership successors are identified and developed for key leadership positions. Purposefully developing leaders through a mentorship and/or succession plan may help eliminate some of the barriers identified in this review. There are many nurses who function as leaders every day, but are not in a designated leadership position or recognized. Downey et al. (2011) wrote about the hidden treasure of these informal nurse leaders who work behind the scenes on the units. Identifying nurses who are already demonstrating leadership potential might supply a source for future leadership positions through purposeful mentorship. In addition, Ennis et al. (2016) recommended intentional modeling to help develop clinical nurse leaders. Modeling and leading by example may be valid methods to help develop junior nurse leadership skills.

Webb et al. (2017) recommend the use of career mapping by education specialists and nurse managers to facilitate professional development of nurses. The authors reported positive outcomes from using the career mapping model to provide structure within an evidence-based process resulting in enhanced professional development, career advancement, and succession planning within a children's hospital (Webb et al. 2017). Collins (2009) discovered that 55.2\% of US hospital CEOs surveyed indicated that their organization had some sort of succession program in place. This percentage was an increase over the 2005 survey of hospital CEUs which indicated about $21 \%$ had some type of succession program (Collins 2009). Patidar et al. (2016) discovered a positive relationship between the presence of succession planning and financial performance in hospitals that had a succession planning program. Patidar et al. (2016) suggests that succession planning may actually protect an organization from disruptive events associated with leadership changes and provide stability even amid a turbulent external environment. Effective succession planning might be a potential solution to many of the leadership barriers identified during this review.

However, several of the studies reviewed suggested a need for formal nurse leadership training. Cummings et al. (2008) found, through a systematic review, that nursing leadership development was fostered through specific educational activities and by modeling and practicing competencies learned (Cummings et al. 2008). These studies support the hypothesis that educational leadership development programs can positively enhance nursing leadership and that leadership skills can be learned.

There are several professional nursing organizations that have developed formal nurse leadership programs to provide training for aspiring nurse leaders. The National League for Nursing (NLN) developed a Leadership Institute with three, full-year programs, to help nurse faculty develop strong leadership skills. The NLN LEAD program is designed for nurses who have experienced a rapid transition into a leadership position or who aspire to lead. The NLN sponsors a Leadership development program for simulation educators to prepare a nurse 
educator for a leadership role in simulation. The NLN Executive leadership in nursing education and practice program is designed for nurse leaders who have held their positions for more than five years (NLN 2017).

The American Nurses Association also created nurse leadership programs. The ANA sponsors several online courses and in person seminars to meet a widerange of nurse leadership needs. Furthermore, the American Organization of Nurse Executives (AONE) sponsors an Emerging Nurse Leader Institute to help shape aspiring nurse mangers into leaders for tomorrow. AONE also sponsors the Executive Fellowship in Innovation Health Leadership, a year-long program to develop the skills needed for executive nurse leadership roles. A limitation of some of these formal courses is the expensive cost and time commitment to complete the programs.

The barriers related to nurses enacting their leadership role is very complicated. The restrictions that prevent the advanced practice nurses from practicing to the full scope of their practice requires change on a policy and board level. The Institute of Medicine committee recommends a reform of the advanced practice registered nurses regulations and even encourages a federal government role in driving the reform (Institute of Medicine 2010). Overcoming these types of challenges are going to require that nurses increase their involvement on boards and committees that influence policy. One major reason identified by Latimer (2015) for nurses not serving on these boards is the limited expertise of nurses serving in the role of trustee. The nurses may not understand what their responsibilities, particularly in the areas of upholding fiduciary obligations. Liabilities and fiduciary duties were the two areas nurses identified as being least likely to be informed about across all organizational boards (Walton et al. 2015. Arms and Stalter (2016) proposes six competencies needed by nurses who serve on boards and/or policy committees. Board members need a professional commitment to serve, knowledge about board types, bylaws and job descriptions and an understanding of standard business protocols. In addition, board members need to understand the roles and voting process and be willing to use principles for managing and leading efficient board meetings. Finally, the board members need to have an ability to employ strategies for maintaining control during uncivil situations and an appreciation for the ethical and legal processes of conducting meetings (Arms and Stalter 2016). The authors conclude that a knowledge of these rules and a demonstration of the identified competencies are essential for nurses to assume leadership roles on boards (Arms and Stalter 2016). The Northwest Organization of Nurse Executives has put together a program to introduce nurse leaders to the board membership role (Brown 2015). Better preparation for board experiences will help future nurses overcome barriers to becoming a valuable contributor to health care policy development.

Perhaps a strategy for overcoming barriers to leadership development is to increase the use of theory in leadership development programs and in the practice of nursing leadership. Transformational and authentic leadership theories have been popular with nurse leadership studies in recent years. Both transformational and authentic leadership theories can be categorized as relational leadership theories. Cowden et al. (2011) discovered that relational leadership approaches 
tended to have more positive nursing outcomes as compared to more task-focused leadership styles. Transformational leadership has been positively associated with intent to stay (Brewer et al. 2016), negatively associated with incivility (Kaiser 2017), associated with higher levels of nurse engagement (Lewis and Cunningham 2015), and positive effects on safety compliance (Lievens and Vlerick 2013).

Transformational leadership is composed of four components: Idealized influence, inspirational motivation, intellectual stimulation and individualized consideration (Bass and Riggio 2008). According to Bass (1990) attaining charisma is a source of great power and influence for the transformational leader. Transformational leaders pay close attention to individual differences and mentor those who need to grow and develop. The leaders are willing and able to intellectually stimulate employees to examine new ways of looking at old problems. Transformational leaders achieve results in one of two ways: they meet their employees' emotional needs or they intellectually stimulate their employees. Transformational leadership can be learned and research has shown that leaders at all levels can be trained to be charismatic (Bass 1990).

Authentic leadership has been associated with reduced nursing burnout (Laschinger et al. 2015), greater work engagement (Bamford et al. 2013), a reduction in workplace bullying and turnover intention (Laschinger et al. 2012), and establishing and sustaining healthy work environments (American Association of Critical-Care Nurses 2016). Avolio and Gardner (2005) propose that authentic leaders foster follower development through self-awareness, self-regulation, and positive modeling. "Authentic leaders are those who aware of their own strengths and weaknesses, consider all other sides of any issue, uphold their personal moral values, and clearly communicate the rationale and goals behind their actions" (Woolley et al. 2011: 439). One of the key differences between the transformational leader and the authentic leader is the way in which followers develop as leaders. Authentic leaders tend to role model behaviors that are picked up by the followers through authentic relationships, whereas transformational leads are more active in seeking to develop a follower into a leader (Avolio and Gardner 2005).

Nursing is a vital part of the ever changing healthcare environment. Developing effective nurse leaders is a priority. Future research should focus on developing strategies that promote effective nurse leadership development and methods to evaluate the organizational outcomes related to these training programs.

\section{References}

Abualrub RF, Alghamdi MG (2012) The impact of leadership styles on nurses' satisfaction and intention to stay among Saudi nurses. Journal of Nursing Management 20: 668-678.

American Hospital Association (2014) National Health Care Governance Survey Report Center for Healthcare Governance. Chicago, IL. Retrieved from goo.gl/ Jrms8U [Accessed: October 17, 2017].

American Association of Critical-Care Nurses (2016) AACN standards for establishing and sustaining healthy work environments: A journey to excellence $\left(2^{\text {nd }}\right.$ Ed.). Retrieved from goo.gl/jzcBKY. [Accessed: 29 May2017] 
American Nurses Association (2016) Nurses on boards-By the number. The American Nurse, 48(3).

American Nurses Association (May/Jun 2015). Nurses on Boards Coalition reports on progress. The American Nurse 47(3).

Avolio BJ, Gardner WL (2005) Authentic leadership development: Getting to the root of positive forms of leadership. The Leadership Quarterly 16(3): 315-338.

Bamford M, Wong CA, Laschinger H (2013) The influence of authentic leadership and areas of worklife on work engagement of registered nurses. Journal of Nursing Management 21(3): 529-540.

Bass BM (1990) From Transactional to transformational leadership: Learning to share the vision. Organizational Dynamics 18(3): 19-31.

Bass BM, Riggio RE (2008) Transformational Leadership ( $2^{\text {nd }}$ Ed.). Mahwah, NJ: Taylor Erlbaum Associates, Inc.

Bondas T (2006) Paths to nursing leadership. Journal of Nursing Management 14(5): 332-339.

Bortoluzzi G, Caporale L, Palese A (2014) Does participative leadership reduce the onset of mobbing risk among nurse working teams? Journal of Nursing Management 22(5): 643-652.

Bressan V, Tolotti A, Barisone M, Bagnasco A, Sasso L, Aleo G et al. (2016) Perceived barriers to the professional development of modern nursing in Italy - a discussion paper. Nurse Education in Practice 17(March): 52-57.

Brewer CS, Kovner CT, Djukie M, Fatehi F, Greene W, Chacko TP et al. (2016) Impact of transformational leadership on nurse work outcomes. Journal of Advanced Nursing 72(11): 2879-2893.

Brown L (2015) Educating nurse leaders for board service: The northwest organization of nurse executives' story. Nursing Administration Quarterly 39(1): 28-31.

Cowden T, Cummings G, Profetto-McGrath J (2011) Leadership practices and staff nurses' intent to stay: A systematic review. Journal of Nursing Management 19(4): 461-477.

Collette K (2015) Leadership style and patient safety: Implications for nurse managers. The Journal of Nursing Administration 45(6): 319-324.

Collins SK (2009) Succession planning: Perspectives of chief executive officers in US hospitals. The Health Care Manager 28(3): 258-263.

Cummings G, Lee H, MacGregor T, Davey M, Wong C, Paul L et al. (2008) Factors contributing to nursing leadership: A systematic review. Journal of Health Services Research and Policy 13(4): 240-248.

Cummings GG, MacGregor T, Davey M, Lee H, Wong CA, Lo E et al. (2010) Leadership styles and outcome patterns for the nursing workforce and work environment: A systematic review. International Journal of Nursing Studies 47: 363-385.

Denker AL, Sherman RO, Hutton-Woodland M, Brunell ML, Medina P (2015) Florida nurse leader survey findings: Key leadership competencies, barriers to leadership and succession planning needs. The Journal of Nursing Administration 45(7/8): 404-410.

Downey M, Parslow S, Smart M (2011) The hidden treasure in nursing leadership: Informal leaders. Journal of Nursing Management 19(4): 517-521.

Dwyer D (2011) Experiences of registered nurses as managers and leaders in residential aged care facilities: A systematic review. International Journal of Evidence-Based Healthcare 9(4): 388-402.

Elliott N, Begley C, Sheaf G, Higgins A (2016) Barriers and enablers to advanced practitioners' ability to enact their leadership role: A scoping review. International Journal of Nursing Studies 60: 24-60. 
Ennis G, Happell B, Reid-Searl (2016) Intentional modeling: A process for clinical leadership development in mental health nursing. Issues in Mental Health Nursing 37(5): 353-359.

Farag A, Anthony MK, Tullai-McGuinnes S, Burant C (2017) Do leadership style, unit climate, and safety climate contribute to safe medication practices? Journal of Nursing Administration 47(1): 8-15.

Fealy GM, McNamara MS, Casey M, Geraghty R, Butler M, Halligan P et al. (2011) Barriers to clinical leadership development: Findings from a national survey. Journal of Clinical Nursing 20(13-14): 2023-2032.

Institute of Medicine (2010) The future of nursing: Leading change, advancing health. Washington, D.C.: The National Academies Press.

Kaiser JA (2017) The relationship between leadership style and nurse-to-nurse incivility: Turning the lens inward. Journal of Nursing Management 25(2): 110-118. .

Keys Y (2014) Looking ahead to our next generation of nurse leaders: Generation X nurse managers. Journal of Nursing Management 22(1): 97-105.

Laschinger HK, Wong CA, Grau AL (2012) The influence of authentic leadership on newly graduated nurses' experiences of workplace bullying, burnout, and retention outcomes: A cross-sectional study. International Journal of Nursing Studies 49(10): 1266-1276.

Laschinger HK, Borgogni L, Consiglio C, Read E (2015) The effects of authentic leadership, six areas of worklife, and occupational coping self-efficacy on new graduate nurses' burnout and mental health: A cross-sectional study. International Journal of Nursing Studies 52(6): 1080-1089.

Latimer GE (2015) Trustee: The basics of boards. Nursing Administration Quarterly 39(1): 18-22.

Lewis HS, Cunningham CJL (2015) Linking nurse leadership and work characteristics to nurse burnout and engagement. Nursing Research 65(1): 13-23.

Liang H, Tang F, Wang T, Lin K, Yu S (2016) Nurse characteristics, leadership, safety climate, emotional labour and intention to stay for nurses: A structural equation modelling approach. Journal of Advanced Nursing 72(12): 3068-3080.

Lievens I, Vlerick P (2013) Transformational leadership and safety performance among nurses: The mediating role of knowledge-related job characteristics. Journal of Advanced Nursing 70(3): 651-661.

Ma C, Shang J, Bott MJ (2015) Linking unit collaboration and nursing leadership to nurse outcomes and quality of care. Journal of Nursing Administration 45(9): 435-442.

Mass H, Brunke L, Thorne S, Parslow HG (2006) Preparing the next generation of senior nursing leaders in Canada: Perceptions of role competencies and barriers from the perspectives of inhabitants and aspirants. Nursing Leadership 19(2): 75-91.

Morsiani G, Bagnasco A, Sasso L (2016) How staff nurses perceive the impact of nurse managers' leadership style in terms of job satisfaction: A mixed method study. Journal of Nursing Management 25(2): 119-128.

NLN - National League for Nursing. Leadership Institute. Retrieved from goo.gl/3k QZK7. [Accessed: 29 May 2017]

Newhouse R, Dearholt S, Poe S, Pugh LC, White K (2005). The Johns Hopkins Nursing Evidence-Based Practice Model and Guidelines ( $1^{\text {st }}$ Ed.). Indianapolis, Indiana: Honor Society of Nursing, Sigma Theta Tau International.

Patidar N, Gupta S, Azbik G, Weech-Maldonado R (2016) Succession planning and financial performance: Does competition matter? Journal of Healthcare Management 61(3): 215-227. 
Peltzer JN, Ford DJ, Shen Q, Fischgrund A, Teel CS, Pierce J et al. (2015) Exploring leadership roles, goals, and barriers among Kansas registered nurses: A descriptive cross-sectional study. Nursing Outlook 63(2): 117-123.

Rankin J, McCuire C, Matthews L, Russell M, Ray D (2016) Facilitators and barriers to the increased supervisory role of senior charge nurses: A qualitative study. Journal of Nursing Management 24(3): 366-375.

Shariff N (2014) Factors that act as facilitators and barriers to nurse leaders' participation in health policy development. BMC Nursing 13(20).

Stalter AM, Arms D (2016) Serving on organizational boards: What nurses need to know. Online Journal of Issues in Nursing 21(2).

Walton A, Lake D, Mullinix C, Allen D, Mooney K (2015) Enabling nurses to lead change: The orientation experiences of nurse to boards. Nursing Outlook 63(2): 110-116.

Webb T, Jeffs D, Diamond-Wells T (2017). Career mapping for professional development and succession planning. Journal for Nurses in Professional Development 33(1): 25-32.

Weng R, Huang C, Chen L, Chang L (2015) Exploring the impact of transformational leadership on nurse innovation behavior: A cross-sectional study. Journal of Nursing Management 23(4): 427-439.

Wooley L, Caza A, Levy L (2011) Authentic leadership and follower development: Psychological capital, positive work climate, and gender. Journal of Leadership and Organizational Studies 18(4): 438-448.

Wong CA, Cummings GG, Ducharme L (2013) The relationship between nursing leadership and patient outcomes: A systematic review update. Journal of Nursing Management 21(5): 709-724. 
